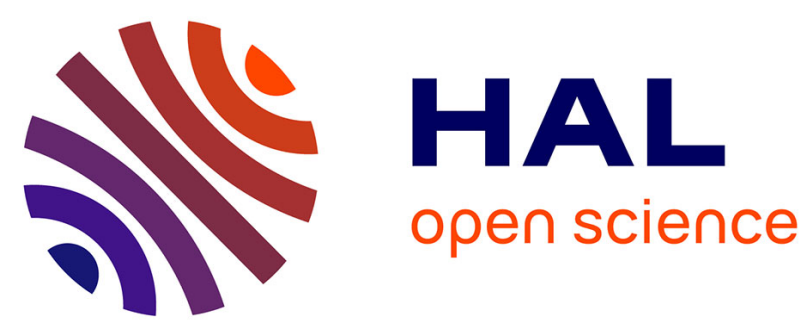

\title{
A chemical kinetic approach to estimate dynamic shear stress during the 1999 Taiwan Chi-Chi earthquake
}

Tetsuro Hirono, Tadashi Yokoyama, Yohei Hamada, Wataru Tanikawa, Toshiaki Mishima, Minoru Ikehara, Vincent Famin, Masaharu Tanimizu, Weiren Lin, Wonn Soh, et al.

\section{To cite this version:}

Tetsuro Hirono, Tadashi Yokoyama, Yohei Hamada, Wataru Tanikawa, Toshiaki Mishima, et al.. A chemical kinetic approach to estimate dynamic shear stress during the 1999 Taiwan Chi-Chi earthquake. Geophysical Research Letters, 2007, 34 (19), pp.L19308. 10.1029/2007GL030743 . hal01386681

\section{HAL Id: hal-01386681 \\ https://hal.science/hal-01386681}

Submitted on 24 Oct 2016

HAL is a multi-disciplinary open access archive for the deposit and dissemination of scientific research documents, whether they are published or not. The documents may come from teaching and research institutions in France or abroad, or from public or private research centers.
L'archive ouverte pluridisciplinaire HAL, est destinée au dépôt et à la diffusion de documents scientifiques de niveau recherche, publiés ou non, émanant des établissements d'enseignement et de recherche français ou étrangers, des laboratoires publics ou privés. 


\title{
A chemical kinetic approach to estimate dynamic shear stress during the 1999 Taiwan Chi-Chi earthquake
}

\author{
Tetsuro Hirono, ${ }^{1}$ Tadashi Yokoyama, ${ }^{1}$ Yohei Hamada, ${ }^{1}$ Wataru Tanikawa, ${ }^{2}$ \\ Toshiaki Mishima, ${ }^{3}$ Minoru Ikehara, ${ }^{4}$ Vincent Famin, ${ }^{5}$ Masaharu Tanimizu, ${ }^{2}$ \\ Weiren Lin, ${ }^{2}$ Wonn Soh, ${ }^{2}$ and Sheng-Rong Song ${ }^{6}$ \\ Received 20 May 2007; revised 31 August 2007; accepted 5 September 2007; published 12 October 2007
}

[1] Estimation of the dynamic shear stress on a fault during an earthquake is important for understanding the earthquake itself. Using a chemical kinetic approach, we examined the thermal decomposition of carbonate minerals to estimate the shear stress on the Taiwan Chelungpu fault, which slipped during the 1999 Chi-Chi earthquake. The reaction rate of the decomposition was related to temperature by using the Arrhenius equation, and the chemical kinetics, taking into account the temperature change over time caused by frictional heating and heat conduction, was solved by the finite difference method. The dynamic shear stress during the Chi-Chi earthquake was deduced to be $1.31 \mathrm{MPa}$, and the frictional coefficient to be $0.04-0.05$. This estimated value agrees with the hypothesis that friction along the Chelungpu fault was low. Citation: Hirono, T., et al. (2007), A chemical kinetic approach to estimate dynamic shear stress during the 1999 Taiwan Chi-Chi earthquake, Geophys. Res. Lett., 34, L19308, doi:10.1029/ 2007GL030743.

\section{Introduction}

[2] Dynamic shear stress during an earthquake is the most important parameter for understanding seismic radiation, the rupture process, the faulting mechanism, friction on the fault, and so on [e.g., Scholz, 2002]. Frictional heating is thought to occur during an earthquake [e.g., Brune et al., 1969; Lachenbruch and Sass, 1980; Scholz, 2002], and the shear stress can be estimated from the temperature recorded in the fault. Temperatures in the faults have been measured in boreholes of active-fault drilling projects such as SAFOD (San Andreas Fault Observatory at Depth) [Williams et al., 2004] and TCDP (Taiwan Chelungpu-fault Drilling Project) [Kano et al., 2006], and numerous rock sample observations and analyses have been also performed not only in natural

\footnotetext{
${ }^{1}$ Department of Earth and Space Science, Graduate School of Science, Osaka University, Toyonaka, Japan.

${ }^{2}$ Kochi Institute for Core Sample Research, Japan Agency for MarineEarth Science and Technology, Nankoku, Japan.

${ }^{3}$ Research Center for Inland Seas, Kobe University, Kobe, Japan

${ }^{4}$ Center for Advanced Marine Core Research, Kochi University, Nankoku, Japan.

${ }^{5}$ Laboratoire des Sciences de la Terre, Institut de Physique du Globe de Paris, Faculté des Sciences et Technologies, Université de la Réunion, Saint-Denis, Réunion Island, France.

${ }^{6}$ Department of Geosciences, National Taiwan University, Taipei, Taiwan.
}

Copyright 2007 by the American Geophysical Union. 0094-8276/07/2007GL030743\$05.00 fault but also in experimented fault [e.g., Otsuki et al., 2003; O'Hara, 2004; Fukuchi et al., 2005].

[3] Some chemical reactions occur because of frictional heating during earthquake events. Hirono et al. [2006a, 2006b, 2007] reported high magnetic susceptibility and low inorganic carbon content from the fault gouge of the Taiwan Chelungpu fault that might have resulted from the formation of magnetic minerals from paramagnetic minerals [Mishima et al., 2006], and thermal decomposition of carbonate minerals, respectively. Kuo et al. [2005] reported relatively low contents of clay minerals within the Chelungpu fault, and suggested that frictional heating during an earthquake had induced dewatering of clay mineral. The relationship between the amount of matter affected by a reaction and the reaction time can be expressed in terms of chemical kinetics, and the reaction rate can be related to temperature by using the Arrhenius equation. However, the temperature in the fault zone during an earthquake is not constant, but changes with time as a result of frictional heating and heat conduction. In this paper, we used a chemical kinetic approach, taking into account the change in temperature with time associated with frictional heating and heat conduction, to examine the thermal decomposition of carbonate minerals to estimate the dynamic shear stress during the 1999 Taiwan Chi-Chi earthquake on the Chelungpu fault, and then deduced the frictional coefficient of the fault.

\section{Low Inorganic Carbon Content in the Taiwan Chelungpu Fault}

[4] The 1999 Taiwan Chi-Chi earthquake ( $\mathrm{M}_{\mathrm{w}}$ 7.6), with epicenter at $23.853 \mathrm{~N}$ and $120.816 \mathrm{E}$ and a focal depth of $8 \mathrm{~km}$ [Ma et al., 1999], occurred on 21 September 1999 (Figure 1). The earthquake initiated on the southern Chelungpu fault and ruptured both upward and laterally northward, and the largest ground velocities and displacements, up to $3 \mathrm{~m} / \mathrm{s}$ and $8 \mathrm{~m}$, respectively, and a low level of highfrequency radiation were recorded in the northern end of the Chelungpu fault [Shin and Teng, 2001]. These seismological behaviors may have resulted from a low level of friction along the fault in this area [e.g., Ma et al., 2003]. The TCDP was therefore undertaken to investigate the faulting mechanism of the Chi-Chi earthquake. Core samples were recovered from two holes: Hole A (total depth $2003.00 \mathrm{~m}$ ) and Hole B (total depth $1352.60 \mathrm{~m}$ ). Three dominant fault zones, FZB1136 (fault zone around $1136 \mathrm{~m}$ depth in Hole B), FZB1194, and FZB1243, were observed within the Chinshui Shale (Figure 1) and interpreted as segments of the Chelungpu fault [Hirono et al., 2006b, 2007]. 


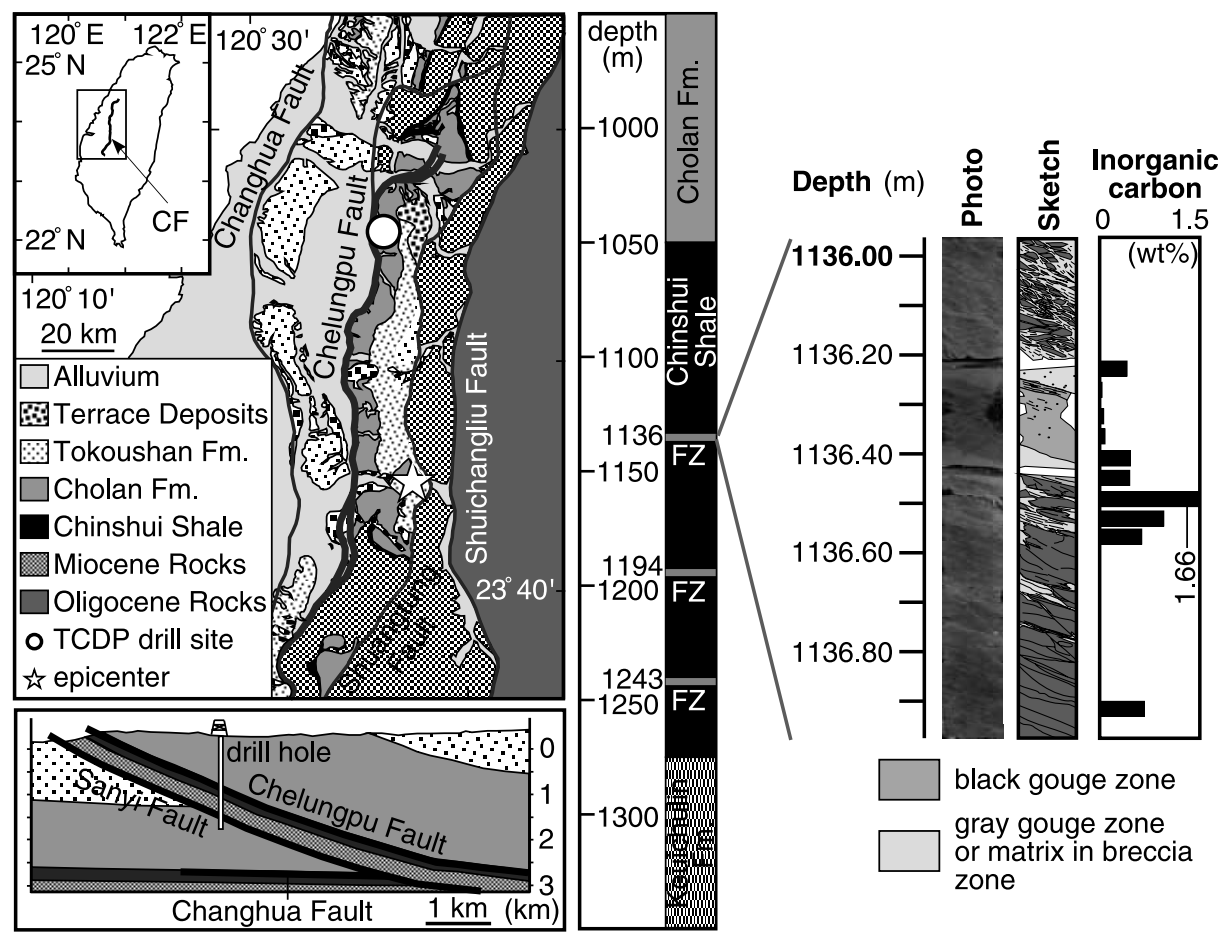

Figure 1. Geological map of central Taiwan showing the site of the Taiwan Chelungpu-fault Drilling Project (TCDP), an E-W cross section through the drill hole site, a core photo and interpretive sketch around the black gouge zone in FZB1136, and results of inorganic carbon content measurements. CF, Chelungpu fault; FZ, fault zone.

[5] Hirono et al. [2006a] reported low inorganic carbon contents in the black gouge zones and disk-shaped black materials (BM disks) within FZB1194 and FZB1243, and identified the latter as pseudotachylytes by a low degree of melting. Ikehara et al. [2007] reported low inorganic carbon content in the black gouge zone within FZB1136. The average inorganic carbon contents of black gouge and BM disks within each fault zone and those of the surrounding rocks are summarized in Table 1. Because FZB1136 was most likely related to the 1999 Chi-Chi earthquake [Kano et al., 2006; Ma et al., 2006; Wu et al., 2007], the inorganic carbon contents around the black gouge zone within FZB1136 were considered to be representative of the temperatures of that event (Figure 1). Although inorganic carbon, as measured by coulometric titration [Ikehara et al., 2007], can be incorporated as the $\mathrm{CO}_{3}^{2-}$ species in carbonate minerals such as calcite $\left(\mathrm{CaCO}_{3}\right)$, dolomite $\left(\mathrm{CaMg}\left(\mathrm{CO}_{3}\right)_{2}\right)$, and siderite $\left(\mathrm{FeCO}_{3}\right)$, X-ray diffraction analysis identified only calcite, which indicates that calcite was the major component of the carbonate minerals within the Chelungpu fault.

\section{Chemical Kinetics of the Thermal Decomposition of Calcite}

[6] The chemical reaction for thermal decomposition of calcite is

$$
\mathrm{CaCO}_{3}(\mathrm{~s}) \rightarrow \mathrm{CaO}(\mathrm{s})+\mathrm{CO}_{2}(\mathrm{~g}) .
$$

Extensive work has been carried out to determine the reaction mechanism and to deduce the kinetic parameters of the decomposition process [e.g., L'vov et al., 2002]. The kinetics of the reaction are commonly expressed as follows:

$$
\frac{d \alpha}{d t}=k f(\alpha)
$$

and also

$$
g(\alpha)=\int_{0}^{\alpha} \frac{d \alpha}{f(\alpha)}=k t,
$$

where $\alpha$ is the degree of conversion (here, decomposition; $0 \leq \alpha \leq 1, \alpha=1$ means totally converted), $t$ is the reaction time, $k$ is the reaction rate, and $f(\alpha)$ and $g(\alpha)$ are kinetic functions determined by the reaction mechanism. Possible mechanisms and their expressions have been summarized in previous work [e.g., Yue et al., 1999]. Although it has been reported that the reaction mechanism and kinetics are affected by many factors, such as heat transfer, $\mathrm{CO}_{2}$ pressure, crystal structure and orientation, and particle size and shape [e.g., Beruto et al., 2004], we here adopted a phase boundary controlled reaction; $f(\alpha)=(1-\alpha)^{2 / 3}$ and also $g(\alpha)=3\left[1-(1-\alpha)^{1 / 3}\right]$ [Criado et al., 1995].

[7] The relationship between reaction rate and temperature, as expressed by the Arrhenius equation, is

$$
k=A \exp \left(\frac{-E_{a}}{R T}\right)
$$

where $A$ is a constant (pre-exponential term), $E_{a}$ is the activation energy necessary for a reaction to occur, $R$ is the gas constant $\left(8.31447 \mathrm{JK}^{-1} \mathrm{~mol}^{-1}\right)$, and $T$ is temperature $(\mathrm{K})$ without a consideration of $\mathrm{CO}_{2}$ pressure for simplicity. 
Table 1. Calculation of the Fraction of Decomposed Calcite Within the Black Gouge Zones and Disk-Shaped Black Materials of the Chelungpu Fault System ${ }^{a}$

\begin{tabular}{lcccc}
\hline \multicolumn{1}{c}{ Type of Zone } & $\begin{array}{c}\text { Inorganic } \\
\text { Carbon Content in } \\
\text { the Zone, wt } \%\end{array}$ & $\begin{array}{c}\text { Inorganic } \\
\text { Carbon Content in } \\
\text { Host Rocks, wt } \%\end{array}$ & $\begin{array}{c}\text { Decomposed } \\
\text { Amount, wt \% }\end{array}$ & $\begin{array}{c}\text { Fraction of } \\
\text { Decomposition }\end{array}$ \\
\hline BGZ in FZB1136 & 0.05 & 0.63 & 0.58 & 0.92 \\
BGZ in FZB1194 & 0.24 & 0.43 & 0.19 & 0.44 \\
BM disk in FZB1194 & 0.05 & 0.43 & 0.29 & 0.88 \\
BGZ in FZB1243 & 0.22 & 0.51 & 0.47 & 0.57 \\
BM disk in FZB1243 & 0.04 & 0.51 & 0.92 \\
\hline
\end{tabular}

${ }^{\mathrm{a}} \mathrm{BGZ}$, black gouge zones; BM disk, disk-shaped black materials. Original data from Ikehara et al. [2007].

From equations (3) and (4), the relationship between reaction time and temperature is therefore

$$
t=3\left[1-(1-\alpha)^{\frac{1}{3}}\right]\left[A \exp \left(\frac{-E_{a}}{R T}\right)\right]^{-1} .
$$

[8] We first calculated the amount of calcite decomposed by heating in the Chelungpu fault by assuming that the inorganic carbon content in the fault zone was in calcite, and that of the surrounding rock represented the initial inorganic carbon content before the earthquake. We could then deduce the amount of calcite that had decomposed in the different parts of each of the three fault zones, and determine, $\alpha$, the fraction decomposed (Table 1). Criado et al. [1995] reported the following values for parameters of the Arrhenius equation: $A$ and $E_{a}$, as $2.68 \times 10^{7} \mathrm{~s}^{-1}$ and $187 \mathrm{~kJ} \mathrm{~mol}^{-1}$, respectively, for calcium carbonate under a condition of low $\mathrm{CO}_{2}$ pressure $(1.3 \mathrm{kPa})$. Consequently, the remaining unknown parameters for the kinetics of calcite decomposition are only reaction time and temperature, and their relationship on the black gouge and BM disk within each fault zone can be represented as shown in Figure 2.

[9] If reaction time is known, temperature necessary for the decomposition reaction to take place can be determined. However, the temperature in the fault zone during an earthquake is not constant, but changes with time as a result of frictional heating and heat conduction.

\section{Temperature Profile Changes Over Time Caused by Frictional Heating and Conduction}

[10] We reconstructed a thermal history, including frictional heating and heat conduction on the basis of Cardwell et al. [1978]. A temperature rise, $\Delta T$, caused by friction along a fault with no heat loss is expressed as

$$
\Delta T=\frac{\tau \nu t_{r}}{w C_{p} \rho}
$$

where $\tau$ is the shear stress, $\nu$ is the slip velocity, $t_{r}$ is the slip time (seismological risetime), $w$ is the thickness of the slip zone, and $C_{p}$ and $\rho$ are the specific heat and density, respectively, of the fault gouge. On the other hand, heat conduction from frictional heat generation with finite thickness is expressed

$$
\begin{aligned}
T(x, t)=T_{0} & +\frac{\Delta T}{2 t_{r}} \int_{0}^{t r} . \\
& \cdot\left\{\operatorname{erf} \frac{x+\frac{w}{2}}{2 \sqrt{D\left(t-t_{0}\right)}}-\operatorname{erf} \frac{x-\frac{w}{2}}{2 \sqrt{D\left(t-t_{0}\right)}}\right\} d t_{0},
\end{aligned}
$$

where $x$ is the distance from the center of heat generation, $t$ is the time for heat conduction including slip time (heating duration), $T_{0}$ is the initial temperature, and $D$ is the thermal diffusivity. $t_{r}$ equals to $t$ at heating stage, and $t_{r}$ is a constant (equals to slip time) after the stage. From equations (6) and (7), the thermal history of a fault zone during earthquake can be expressed

$$
\begin{aligned}
T(x, t)= & T_{0}+\frac{\tau \nu}{2 w C_{p} \rho} \int_{0}^{t r} \\
& \cdot\left\{\operatorname{erf} \frac{x+\frac{w}{2}}{2 \sqrt{D\left(t-t_{0}\right)}}-\operatorname{erf} \frac{x-\frac{w}{2}}{2 \sqrt{D\left(t-t_{0}\right)}}\right\} d t_{0} .
\end{aligned}
$$

\section{Temperature Profile Constrained by Chemical Kinetics}

[11] Because the temperature was not constant but changed with time, determination of the chemical kinetics of the decomposition reaction requires realistic consideration of the temperature profile during an earthquake. From equations (5) and (8), $\alpha$ in the center of the fault zone $(x=0)$ is expressed as

$$
\alpha=\int_{0}^{t s .}\left[1-\left\{1-\frac{A}{3} \exp \left(\frac{-E_{a}}{R\left(T_{0}+\frac{\tau \nu}{w C_{p} \rho} \int_{0}^{t_{r}} \operatorname{erf} \frac{w}{4 \sqrt{D\left(t-t_{0}\right)}} d t_{0}\right)}\right) t\right\}^{3}\right] d t
$$

where $t_{s}$ is the time between the earthquake and sample recovery. We again adopt a phase boundary controlled reaction. The value of $\alpha$ is determined on the basis of inorganic carbon content (Table 1, fraction of decomposition), and among the other parameters, only the value of $\tau$ is unknown. We first calculated the value of $\alpha$ for various values of $\tau$ by the finite difference method, and then obtained a value of $\tau$ consistent with the observed value of $\alpha$. We performed this calculation not only for the black gouge zone within FZB1136, probably including the slip zone of the Chi-Chi earthquake, but also for the other fault zones. We adopted the following values for the other parameters: $A=2.68 \times 10^{7} \mathrm{~s}^{-1}$ and $E_{a}=187 \mathrm{~kJ} \mathrm{~mol}^{-1}$ [Criado et al., 1995]; $T_{0}=46.5^{\circ} \mathrm{C}$ [Kano et al., 2006]; $\nu=$ $1.38 \mathrm{~m} \mathrm{~s}^{-1}$ calculated from the total displacement of $8.3 \mathrm{~m}$ 
(a)

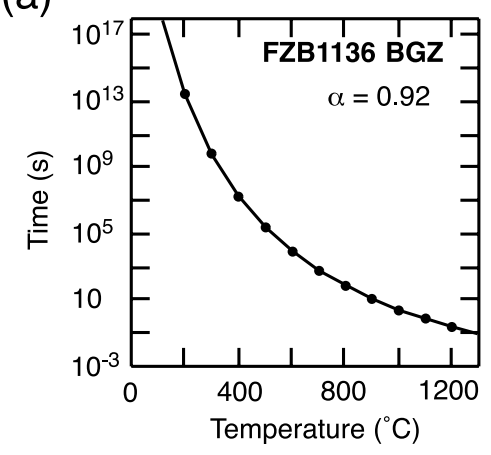

(b)
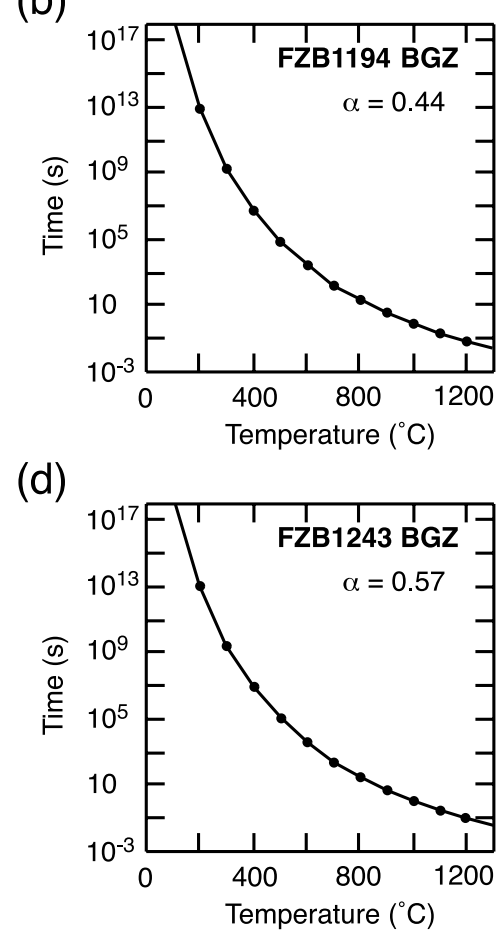

(c)

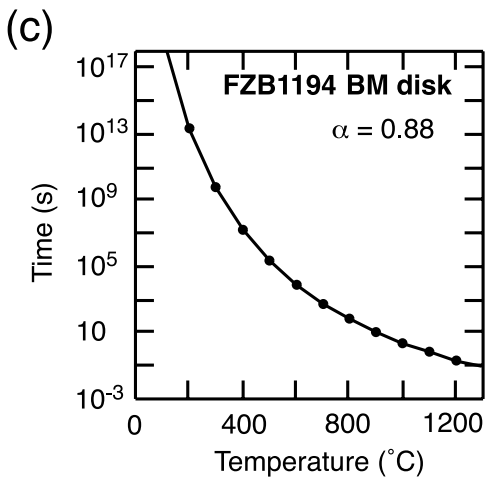

(e)

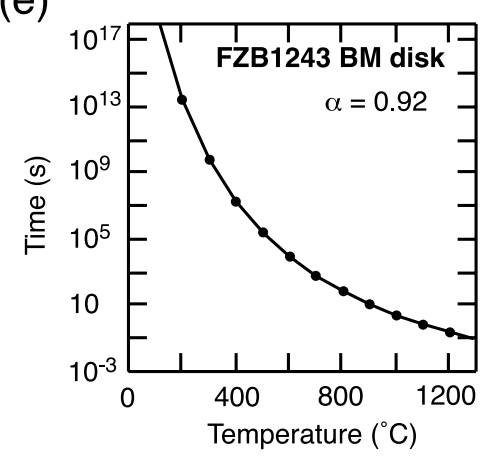

Figure 2. Duration of calcite decomposition as a function of temperature in the three fault zones within the Chelungpu fault system. BGZ, black gouge zone; BM disk, disk-shaped black material. (a) BGZ in FZB1136. (b) BGZ in FZB1194. (c) BM disk in FZB1194. (d) BGZ in FZB1243. (e) BM disk in FZB1243.

[Ma et al., 2006] and slip time of $6 \mathrm{~s}$ [Ma et al., 2003]; $C_{p}=$ $300 \mathrm{Jkg}^{-1} \mathrm{~K}^{-1}$ [Tanaka et al., 2007]; $\rho=2200 \mathrm{~kg} \mathrm{~m}^{-3}$ [Hirono et al., 2006b]; $D=1.0 \times 10^{-6} \mathrm{~m}^{2} \mathrm{~s}^{-1}$ [Tanaka et al., 2007]; and $t_{r}=t$ at $t \leq 6 \mathrm{~s}$, and $t_{r}=6 \mathrm{~s}$ (constant) at $t>6$ s. Because Ma et al. [2006] suggested a major-slipzone thickness of $2 \mathrm{~cm}$ for the Chi-Chi earthquake, we assumed $w=2 \mathrm{~cm}$ for a single earthquake event in the black gouge zone in each fault zone. For the BM disks, we used the disk thickness for $w: 2 \mathrm{~cm}$ for the BM disk in FZB1194 and $3 \mathrm{~cm}$ for that in FZB1243 (from Hirono et al. [2006a]). Because the period between the Chi-Chi earthquake and sample recovery from Hole B was approximately 5 years, $t s=1.58 \times 10^{8} \mathrm{~s}$.

[12] The values of $\tau$ obtained for the black gouge and BM disk within each fault zone were as follows: black gouge zone in FZB1136, 1.31 MPa; black gouge zone in FZB1194, 1.25 MPa; BM disk in FZB1194, $1.31 \mathrm{MPa}$; black gouge zone in FZB1243, $1.27 \mathrm{MPa}$; and BM disk in
FZB1243, 1.85 MPa. The temperature-time profile of each zone was also reconstructed from the solution (Figure 3).

\section{Discussion and Conclusions}

[13] Because Ma et al. [2003] suggested low friction during the 1999 Chi-Chi earthquake, and because FZB1136 most likely slipped during the earthquake [Kano et al., 2006: Ma et al., 2006; Wu et al., 2007], we here calculate the frictional coefficient from the shear stress obtained for the black gouge zone within FZB1136. The effective vertical stress around FZB1136 is $17.8 \mathrm{MPa}$ (rock density, $2600 \mathrm{~kg} \mathrm{~m}^{-3}$, from Hirono et al. [2007]), and dip of the fault plane is $35^{\circ}$ [Hirono et al., 2007]. Assuming that the horizontal stress is equal to the vertical stress, the stress normal to the fault is totally $24.8 \mathrm{MPa}$ (the vertical stress of 14.6 MPa plus the horizontal stress of $10.2 \mathrm{MPa}$ ), resulting in the frictional coefficient of 0.05 . For a thrust fault 
(a)

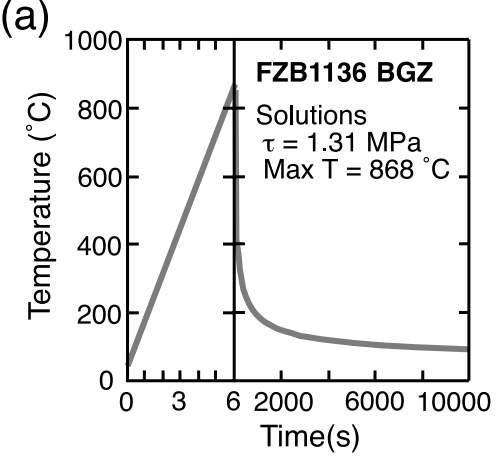

(b)

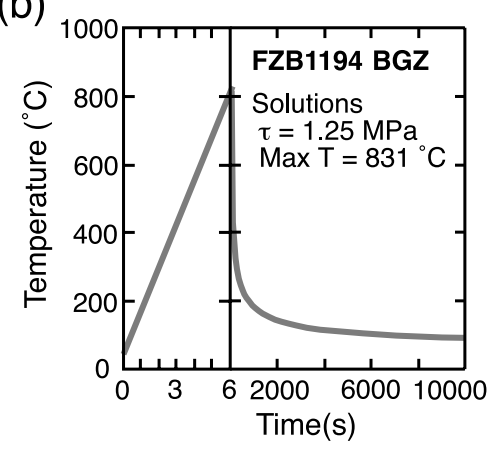

(d)

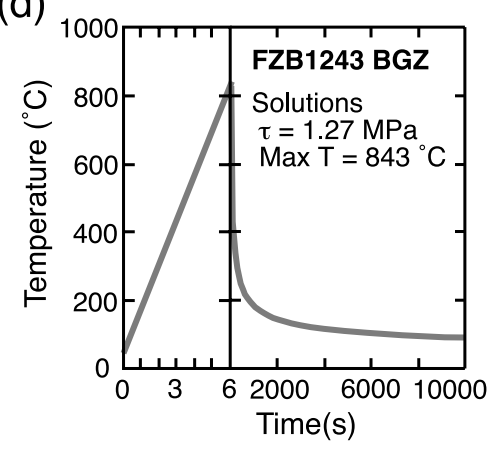

(c)

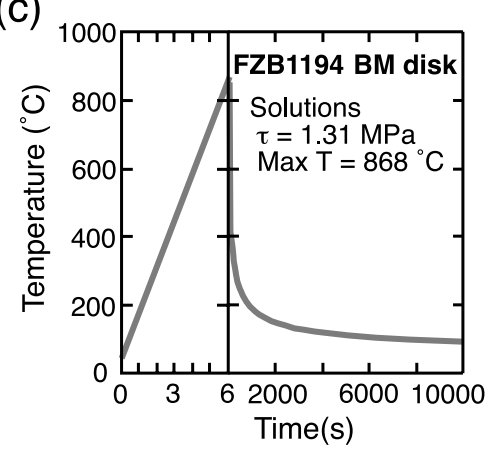

(e)

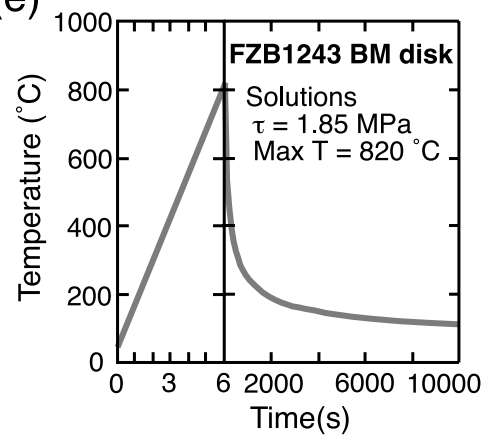

Figure 3. Temperature-time profile reconstructed using the shear stress solution.

environment, the maximum horizontal stress is higher than the vertical stress [Sibson, 1974]. If the horizontal stress is twice as high as the vertical stress, the frictional coefficient is 0.04 . However, the state and magnitude of stress during the seismic rupture might not be the same to the static, so that such a low value of frictional coefficient includes an uncertainty.

[14] To assess the validity of our results, we here raise another issue and discuss the counter argument. The observed amount of calcite decomposition might be the accumulated result of several successive seismic events rather than of a single earthquake. However, this would not have a marked effect on the kinetic estimation, as shown by the similarity of the time-temperature relationships for the black gouge zone in FZB1136 $(a=0.92)$ and the black gouge zone in FZB1194 $(a=0.44)$ (Figure 2). Accurate determination of the reaction mechanisms, of their expression in term of $f(\alpha)$ and $g(\alpha)$, and of the parameters of the Arrhenius equation ( $A$ and $E_{a}$ ) under in situ conditions of the fault zones are important. Measurements of thermal properties such as heat capacity and thermal diffusivity in the fault zone are also indispensable.

Table 2. Calculated Amount of $\mathrm{CO}_{2}$ Released by Thermal Decomposition of Calcite From the Black Gouge Zone and Disk-Shaped Black Materials of the Chelungpu Fault System ${ }^{\mathrm{a}}$

\begin{tabular}{lcccc}
\hline \multicolumn{1}{c}{ Type of Zone } & $\begin{array}{c}\text { Decomposed } \\
\text { Amount, wt } \%\end{array}$ & $\begin{array}{c}\text { Released } \mathrm{CO}_{2} \\
\text { Amount, } \mathrm{g} / \mathrm{cm}^{3}\end{array}$ & $\begin{array}{c}\text { Thickness of } \\
\text { Zone, } \mathrm{cm}\end{array}$ & $\begin{array}{c}\text { Released } \mathrm{CO}_{2} \\
\text { Amount, } \mathrm{g} / \mathrm{m}^{2}\end{array}$ \\
\hline BGZ in FZB1136 & 0.58 & 0.56 & 14 & $7.85 \times 10^{-4}$ \\
BGZ in FZB1194 & 0.19 & 0.18 & 12 & $2.21 \times 10^{-4}$ \\
BM disk in FZB1194 & 0.38 & 0.37 & 2 & $7.35 \times 10^{-5}$ \\
BGZ in FZB1243 & 0.29 & 0.28 & 9 & $2.52 \times 10^{-4}$ \\
BM disk in FZB1243 & 0.47 & 0.45 & 3 & $1.36 \times 10^{-4}$ \\
\hline
\end{tabular}

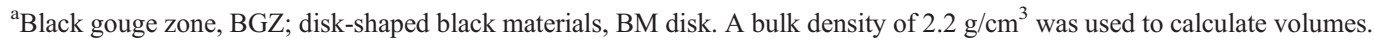


[15] Chemical reactions induced by frictional heating may also affect frictional behavior during an earthquake. For example, thermal decomposition of calcite produces $\mathrm{CO}_{2}$ (equation (1)): the released $\mathrm{CO}_{2}$ (supercritical phase) may reduce the effective normal stress, thus decreasing the friction along the fault. Furthermore, $\mathrm{CO}_{2}$ may be expelled via a fault during and/or after an earthquake. In this study, the amount of $\mathrm{CO}_{2}$ released per $\mathrm{cm}^{3}$ was calculated using the rock density and the amount of calcite decomposed; if the thickness of the fault zone was accurately known, the amount of $\mathrm{CO}_{2}$ released could then be calculated per $\mathrm{m}^{2}$ (Table 2). Further investigation of these influences in active faults is needed.

[16] Finally, we emphasize that a kinetic approach using chemical reaction, such as calcite decomposition, might be valid and useful to estimate the dynamic shear stress during an earthquake and subsequently the frictional coefficient on a fault. Not only the reaction but also the decomposition of organic matter and pyrite, dewatering of clay minerals, and dissolution of minerals into interstitial fluid (at supercritical phase?), can be used as proxies for dynamic shear stress.

[17] Acknowledgments. We thank three anonymous reviewers for their many constructive comments, and we also thank editor Aldo Zollo for editing this paper. This research was supported by Japan Ministry of Education, Science, Sports and Culture, Grant-in-Aid for Young Scientists (B) 18740323, 2007.

\section{References}

Beruto, D. T., A. W. Searcy, and M. G. Kim (2004), Microstructure, kinetic, structure, thermodynamic analysis for calcite decomposition: Freesurface and powder bed experiments, Thermochim. Acta, 424, 99-109.

Brune, J., T. Henyey, and R. Roy (1969), Heat flow, stress, and rate of slip along the San Andreas fault, California, J. Geophys. Res., 74, $3821-$ 3827.

Cardwell, R. K., D. S. Chinn, G. F. Moore, and D. L. Turcotte (1978), Frictional heating on a fault zone with finite thickness, Geophys. J. R. Astron. Soc., 52, 525-530.

Criado, J. M., M. Gonzalez, J. Malek, and A. Ortega (1995), The effect of the $\mathrm{CO}_{2}$ pressure on the thermal decomposition kinetics of calcium carbonate, Thermochim. Acta, 254, 121-127.

Fukuchi, T., K. Mizoguchi, and T. Shimamoto (2005), Ferrimagnetic resonance signal produced by frictional heating: A new indicator of paleoseismicity, J. Geophys. Res., 110, B12404, doi:10.1029/2004JB003485.

Hirono, T., et al. (2006a), Evidence of frictional melting within disk-shaped black material, discovered from the Taiwan Chelungpu fault system, Geophys. Res. Lett., 33, L19311, doi:10.1029/2006GL027329.

Hirono, T., et al. (2006b), High magnetic susceptibility of fault gouge within Taiwan Chelungpu fault: Nondestructive continuous measurements of physical and chemical properties in fault rocks recovered from Hole B, TCDP, Geophys. Res. Lett., 33, L15303, doi:10.1029/2006GL026133.

Hirono, T., et al. (2007), Nondestructive continuous physical property measurements of core samples recovered from Hole B, Taiwan Chelungpufault Drilling Project, J. Geophys. Res., 112, B07404, doi:10.1029/ 2006JB004738.

Ikehara, M., et al. (2007), Low total and inorganic carbon contents within the Chelungpu fault system, Geochem. J., in press.

Kano, Y., J. Mori, R. Fujio, H. Ito, T. Yanagidani, S. Nakao, and K.-F. Ma (2006), Heat signature on the Chelungpu fault associated with the 1999 Chi-Chi, Taiwan earthquake, Geophys. Res. Lett., 33, L14306, doi:10.1029/2006GL026733.
Kuo, L., S. Song, and H. Chen (2005), Characteristics of clay minerals in the fault zone of TCDP and its implications, Eos Trans. AGU, 86(52), Fall Meet. Suppl., Abstract T43D-05.

Lachenbruch, A. H., and J. H. Sass (1980), Heat flow and energetics of the San Andreas fault zone, J. Geophys. Res., 85, 6185-6222.

L'vov, B. V., L. K. Polzika, and V. L. Ugolkov (2002), Decomposition kinetics of calcite: A new approach to the old problem, Thermochim. Acta, 390, 5-19.

Ma, K.-F., C. T. Lee, Y. B. Tsai, T. C. Shin, and J. Mori (1999), The ChiChi Taiwan earthquake: Large surface displacements on inland thrust fault, Eos Trans. $A G U, 80,605$.

Ma, K.-F., E. E. Brodsky, J. Mori, C. Ji, T.-R. A. Song, and H. Kanamori (2003), Evidence for fault lubrication during the 1999 Chi-Chi, Taiwan, earthquake (Mw7.6), Geophys. Res. Lett., 30(5), 1244, doi:10.1029/ 2002 GL015380.

Ma, K. F., H. Tanaka, S. Song, C. Wang, J. Hung, Y. Song, E. Yeh, W. Soh, H. Sone, L. Kuo, and H. Wu (2006), Slip zone and energetics of a large earthquake from the Taiwan Chelungpu-fault Drilling Project, Nature, 444, 473-476.

Mishima, T., T. Hirono, W. Soh, and S.-R. Song (2006), Thermal history estimation of the Taiwan Chelungpu fault using rock-magnetic methods, Geophys. Res. Lett., 33, L23311, doi:10.1029/2006GL028088.

O'Hara, K. (2004), Paleo-stress estimates on ancient seismogenic faults based on frictional heating of coal, Geophys. Res. Lett., 31, L03601, doi:10.1029/2003GL018890.

Otsuki, K., N. Monzawa, and T. Nagase (2003), Fluidization and melting of fault gouge during seismic slip: Identification in the Nojima fault zone and implications for focal earthquake mechanisms, J. Geophys. Res., 108(B4), 2192, doi:10.1029/2001JB001711.

Scholz, C. H. (2002), The Mechanisms of Earthquake Faulting, 496 pp., Cambridge Univ. Press, New York.

Shin, T., and T. Teng (2001), An overview of the 1999 Chi-Chi, Taiwan, earthquake, Bull. Seismol. Soc. Am., 91, 895-2001.

Sibson, R. H. (1974), Frictional constraints on thrust, wrench and normal faults, Nature, 249, 542-544.

Tanaka, H., W. M. Chen, K. Kawabata, and N. Urata (2007), Thermal properties across the Chelungpu fault zone and evaluations of positive thermal anomaly on the slip zones: Are these residuals of heat from faulting?, Geophys. Res. Lett., 34, L01309, doi:10.1029/2006GL028153.

Yue, L., M. Shui, and Z. Xu (1999), The decomposition kinetics of nanocrystalline calcite, Thermochim. Acta, 335, 121-126.

Williams, C. F., F. V. Grubb, and S. P. Galanis Jr. (2004), Heat flow in the SAFOD pilot hole and implications for the strength of the San Andreas Fault, Geophys. Res. Lett., 31, L15S14, doi:10.1029/2003GL019352.

Wu, H.-Y., K.-F. Ma, M. Zoback, N. Boness, H. Ito, J.-H. Hung, and S. Hickman (2007), Stress orientations of Taiwan Chelungpu-Fault Drilling Project (TCDP) hole-A as observed from geophysical logs, Geophys. Res. Lett., 34, L01303, doi:10.1029/2006GL028050.

V. Famin, Laboratoire des Sciences de la Terre, Institut de Physique du Globe de Paris, Faculté des Sciences et Technologies, Université de la Réunion, 15, Avenue René Cassin, BP 7151, F-97715 Saint-Denis messag cedex 9, le Réunion, France.

Y. Hamada, T. Hirono, and T. Yokoyama, Department of Earth and Space Science, Graduate School of Science, Osaka University, Machikaneyamacho 1-1, Toyonaka 560-0043, Japan. (hirono@ess.sci.osaka-u.ac.jp)

M. Ikehara, Center for Advanced Marine Core Research, Kochi University, Monobe-otsu 200, Nankoku 783-8502, Japan.

W. Lin, W. Soh, W. Tanikawa, and M. Tanimizu, Kochi Institute for Core Sample Research, Japan Agency for Marine-Earth Science and Technology, Monobe-otsu 200, Nankoku 783-8502, Japan.

T. Mishima, Research Center for Inland Seas, Kobe University, 1-1 Rokkodai, Nada-ku, Kobe 657-8501, Japan.

S.-R. Song, Department of Geosciences, National Taiwan University, P.O. Box 123-318, Taipei 106, Taiwan. 